\title{
Development of prednisolone-containing eye drop formulations by cyclodextrin complexation and antimicrobial, mucoadhesive biopolymer
}

This article was published in the following Dove Press journal:

Drug Design, Development and Therapy

Tivadar Bíró'

Gabriella Horvát'

Mária Budai-Szűcs'

Erzsébet Csányi'

Edit Urbán ${ }^{2}$

Andrea Facskó ${ }^{3}$

Piroska Szabó-Révész'

Ildikó Csóka'

Zoltán Aigner'

'Institute of Pharmaceutical Technology and Regulatory Affairs, University of Szeged, Szeged,

Hungary; ${ }^{2}$ Department of Clinical

Microbiology, Faculty of Medicine,

University of Szeged, Szeged, Hungary;

${ }^{3}$ Ophthalmology Department, Faculty

of Medicine, University of Szeged,

Szeged, Hungary
Correspondence: Zoltán Aigner Institute of Pharmaceutical

Technology and Regulatory Affairs,

University of Szeged, 6 Eötvös street,

H-6720 Szeged, Hungary

Tel +36 62545577

Email aigner@pharm.u-szeged.hu
Purpose: The formulation of topical ophthalmic products with appropriate therapeutic effect and patient compliance is a major challenge. To increase the efficiency of the ocular delivery of the drug, the enhancement of water solubility and the contact time of the drug on the surface of the cornea are necessary. In this work, prednisolone (PR)-containing eye drops were formulated with antimicrobial, mucoadhesive biopolymer and PR-cyclodextrin inclusion complex. This approach can be used for the development of innovative ophthalmic formulations.

Materials and methods: After adjusting the optimal physiological parameters, the amount of the required cyclodextrin for the highest penetration of PR was determined by dialysis membrane diffusion study. The viscosity, surface tension and mucoadhesion of the eye drops were measured. The microbiological effectiveness of zinc-hyaluronate ( $\mathrm{ZnHA}$ ) was investigated by a standard method of the European Pharmacopoeia.

Results: In this case, no significant difference of surface tension was measured in products with different amounts of cyclodextrin. According to the results of the tensile test, ZnHA as a mucoadhesive biopolymer improves the mucoadhesion of ophthalmic products. The antimicrobial stability of formulations preserved by ZnHA meets requirement B of the European Pharmacopoeia.

Conclusion: It can be stated that the innovative PR-containing compositions are suitable for producing mucoadhesive, properly preserved aqueous ophthalmic solutions with increased bioavailability attributes.

Keywords: pharmaceutical formulation, zinc-hyaluronate, ocular drug delivery, microbiological stability, membrane diffusion

\section{Introduction}

Topical ocular drug delivery is restricted by barriers, such as eye blinking and lachrymal secretion, which result in low bioavailability after application. Solving this problem is a major challenge in the field of research and development and necessary because topically applied formulations have the highest patient adherence in the treatment of eye diseases. ${ }^{1}$

In order to reach an optimal efficiency, the transcorneal penetration of the drug is important. The cornea is composed of five layers: the lipophilic epithelium, the hydrophilic stroma between Descemet's membrane and Bowman's layer, and the lipophilic endothelium. To complete the optimal transcorneal penetration, a balance in the hydrophilicity and lipophilicity of the drug and the vehicle is needed. The continuous secretion of tear fluid rapidly dilutes and washes out the applied eye drop and limits the contact time of drugs on the eye surface. ${ }^{2}$ 
In ophthalmic surgery, glucocorticoid derivatives like prednisolone (PR), dexamethasone and fluorometholone are widely used for postoperative inflammation prophylaxis. Due to their low aqueous solubility, they are present on the market primarily in suspension formulations. When there is a risk of severe inflammation, especially after cornea transplantation, anti-inflammatory steroid therapy is needed by giving a subconjunctival or subretinal injection. ${ }^{2,3}$ Instead of these complicated and uncomfortable invasive applications, it would be more acceptable to use noninvasive, topical, water-soluble corticosteroid-containing eye drop formulations with higher efficiency.

One of the ways to increase efficiency on the eye surface is to solubilize the active pharmaceutical ingredient (API) in aqueous system, thereby ensuring that the optimal concentration of the drug appears near the epithelium of the cornea. Cyclodextrins (CDs) can solubilize lipophilic, waterinsoluble drugs with suitable molecular size and structure, so they can be formulated in aqueous solutions. These cyclic oligosaccharides consist of $\alpha$ - $(1,4)$ linked $\alpha$-D-glucopyranose units. As a result of the lipophilic cavity of $\mathrm{CD}$, an inclusion complex forms with the lipophilic drug molecules, due to thermodynamic interactions. ${ }^{4-7}$ This complex is soluble in water because of the hydrophilic external surface of $\mathrm{CD}$ and can be dissociated in the aqueous tear fluid. As a result, equilibrium is achieved between the complexed and noncomplexed components. The determination of the optimal concentration of $\mathrm{CD}$ is important. With the proper amount of $\mathrm{CD}$, the API can be in aqueous solution permanently, so a sufficient amount of drug molecules appears at the surface of the cornea, which induces the increase of drug permeation. If the concentration of $\mathrm{CD}$ is too low, it is not able to bring about the required water solubility of the drug, whereas too much CD decreases the amount of free, permeable drug molecules at the cornea. ${ }^{8}$ The cytotoxicity of $\beta-\mathrm{CD}$ derivatives was investigated by several research groups on different cell lines. In ophthalmology, the hydroxypropyl derivatives of $\beta$ - and $\gamma$-CDs, the randomly methylated $\beta$-CD and sulfobutylether- $\beta$-cyclodextrin are tolerated because of the preferential cytotoxic properties against cornea epithelial cells..$^{4,9,10}$ Now, licensed CD-containing products are widely used in medical practice. ${ }^{5,6}$

The reflex mechanisms of the eye, such as blinking and lachrymal secretion, result in rapid drug elimination from the surface. To maintain the optimal, therapeutic drug level, more frequent application is needed, which can induce many side effects and decrease patient compliance. This problem can be solved by increasing the contact time of API on the surface of the cornea by increasing the viscosity with inserts, microspheres or mucoadhesive polymers. With longer residence, the penetration rate of API can be increased. ${ }^{11}$ At a needlessly high viscosity level, the reflex mechanisms of the eye, blinking and lachrymation, are induced until the physiological viscosity of the tear is regained. Some viscosity increasing compounds have a mucoadhesive effect. With these materials optimal residual time can be achieved, without increasing viscosity to an unnecessarily high level. The mechanism of mucoadhesion involves tight contact and interpenetration between the mucoadhesive component and the proteoglycan chains of the mucin. Bioavailability can be improved through this mechanism. ${ }^{12,13}$ Hyaluronic acid is a linear anionic polysaccharide, a main component in the extracellular matrix of connective tissue. This biocompatible polymer can aid tissue manipulation and protect the corneal endothelium due to its proliferative effect. It interacts with mucin covering the conjunctival and corneal surfaces of the eye, and as a result ocular mucoadhesion is achieved. ${ }^{14-16}$

Benzalkonium chloride (BK) is a cationic surfactant additive, which is widely used as a microbiological preservative agent in eye drop formulations. BK may destroy the cell membrane of microorganisms, which results in an antimicrobial effect. Toxicity for corneal and conjunctival epithelial cells and incompatibility with contact lenses were reported earlier. ${ }^{17-19}$ BK causes DNA single- and doublestrand breaks in corneal epithelial cells, so the barrier of the eye surface may be damaged. Allergic reaction, eye irritation and increased tear secretion may be caused by application. ${ }^{17-19}$ It is also known that resistance of Pseudomonas aeruginosa against BK appears due to decreasing the permeation through the cell wall. ${ }^{20}$ The antimicrobial properties of $\mathrm{Zn}^{2+}$ ion-containing compounds are favorable in pharmaceutical formulations. Marketed products, like Ophylosa ${ }^{\circledR}$ (Gedeon Richter Plc, Budapest, Hungary) contain zinc-hyaluronate (ZnHA) and zinc-gluconate ( $\mathrm{ZnGlu}$ ) for replacing BK. The antimicrobial effect depends on the reactive oxygen species generating mechanism, the cell wall destabilizing effect of cytotoxic, dissolved $\mathrm{Zn}^{2+}$ ion in a water-based environment. ${ }^{21}$ Zinc-containing polymers like ZnHA could be acceptable, combined with a zinc salt of gluconic acid, ZnGlu, to reach the suitable antimicrobial stability. Further investigation is needed to confirm the capability of these compounds as replacements of the unfavorable BK. ZnHA could be a useful antimicrobial and mucoadhesive additive in ophthalmic formulations. ${ }^{22}$

The aim of this study was to develop an innovative, water-soluble PR-containing eye drop formulation with 
infrequent application, adequate microbiological stability and acceptable physiological (surface tension, $\mathrm{pH}$, osmolality), rheological and mucoadhesive parameters using a CD inclusion complex, and preservative, mucoadhesive $\mathrm{ZnHA}$ and $\mathrm{ZnGlu}$.

\section{Material and methods Materials}

PR was purchased from Henan Lihua Pharmaceutical Company (Henan, China). Hydroxypropyl- $\beta$-cyclodextrin (HPBCD) was obtained from Wacker-Chemie $\mathrm{GmbH}$ (Munich, Germany), hydroxypropyl- $\gamma$-cyclodextrin (HPGCD) was kindly donated by Cyclolab Ltd. (Budapest, Hungary), ZnHA and ZnGlu from Gedeon Richter Plc (Budapest, Hungary). BK, sodium chloride $(\mathrm{NaCl})$, boric acid and borax (for borate buffer) were obtained from Molar Chemical Ltd. (Halásztelek, Hungary). Mucin (porcine gastric mucin type II) was purchased from Sigma-Aldrich (St Louis, MO, USA). Lachrymal fluid of $\mathrm{pH}=7.4$ was prepared by dissolving $2.2 \mathrm{~g} \mathrm{~L}^{-1} \mathrm{NaHCO}_{3}, 6.26 \mathrm{~g} \mathrm{~L}^{-1} \mathrm{NaCl}, 1.79 \mathrm{~g} \mathrm{~L}^{-1} \mathrm{KCl}, 96.4 \mathrm{mg}$ $\mathrm{L}^{-1} \mathrm{MgCl}_{2} \cdot 6 \mathrm{H}_{2} \mathrm{O}$ and $73.5 \mathrm{mg} \mathrm{L} \mathrm{CaCl}_{2} \cdot \mathrm{H}_{2} \mathrm{O}$ in distilled water, the $\mathrm{pH}$ being adjusted with $1 \mathrm{M} \mathrm{HCl}^{23}$

\section{Methods}

\section{Phase solubility test}

The phase solubility of PR was measured by adding it in excess amount to HPBCD- and HPGCD-containing solutions (purified water was used as a solvent) with different concentrations $(0-150 \mathrm{mM})$ and allowing it to be intermixed for 48 hours. Thereafter, the solutions were filtered with a $0.45 \mu \mathrm{m}$ membrane filter (Millex-HV Syringe Driven Filter Unit, $0.45 \mu \mathrm{m}$, EMD Millipore, Billerica, MA, USA) and analyzed with UV spectrophotometry (wavelength: $248 \mathrm{~nm}$, Unicam UV/Vis Spectrometer, ATI Unicam, Cambridge, UK).

The type of diagrams and the ratio of complexes were determined and the stability constants of complexes $\left(\mathrm{K}_{\mathrm{s}}\right)$ were calculated by Equation (1): ${ }^{24,25}$

$$
\mathrm{K}_{\mathrm{s}}=\text { Slope } /\{\text { Intercept }(1-\text { Slope })\}
$$

\section{Preparation of products}

The eye drops in the market contain $1 \%$ or $0.12 \%$ PR-acetate in suspension formulations. According to these products, we use $0.1 \%$ PR as API. Considering the probable improvement of the bioavailability, this amount is suitable and proper therapeutic effect can be expected. Defined amounts of HPGCD or HPBCD was dissolved in borate buffer and $0.5 \%$
ZnHA-ZnGlu-containing aqueous solutions. According to Horvát et al, this amount of ZnHA could not create a viscous, gel-formulation, therefore the unfavorable attributes of high viscosity are not expected. ${ }^{26}$ PR was dissolved in these solutions. Products were put into an ultrasonic bath for 10 minutes. Osmolality was set with $\mathrm{NaCl}$ to about $300 \mathrm{mOsm} \mathrm{kg}^{-1}$; the $\mathrm{pH}$ was about 6.20 in every product. Every eye drop was prepared in aseptic environment.

\section{Study of diffusion through dialysis membrane}

The penetration of API depends on the concentration of CD. Overly high or low amounts of CD can cause a decreased absorption of API, therefore its determination is important. With the investigation of the diffusion of PR through a dialysis membrane, the optimal CD quantity as a function of drug penetration can be adjusted.

The amount of CD for the optimal penetration of API was determined by drug diffusion monitoring. Zellutrans/ Roth cellulose dialysis membrane tube (10 mm wide, $6.4 \mathrm{~mm}$ diameter, MWCO: 12,000-14,000 D) was used for the experiment. The membrane pouches were closed with Spectra/Por Closures. The sample $(2.00 \mathrm{~mL})$ was injected into the pouches and put into $25 \mathrm{~mL}$ of borate buffercontaining aqueous acceptor phase $(\mathrm{pH}=7.4)$ tempered at $35^{\circ} \mathrm{C}$. At various time intervals $(15,30,60,120,180$, and 240 minutes), $1.00 \mathrm{~mL}$ of the sample was removed from the acceptor phase and refilled with the buffered solution. The length of the measurement is reasonable, due to the possible increased retention on the surface of the eye. Four samples were measured parallel at the same time. The PR content was analyzed with UV spectrophotometry.

\section{Viscosity}

A Physica MCR 101 rheometer with cone-plate measuring device (Anton Paar, Graz, Austria, CP25-1, cone angle $0.997^{\circ}, 25 \mathrm{~mm}$ diameter) was used for the measurement. The formulations were investigated at $25^{\circ} \mathrm{C}$; the shear rate was increased from $0.1 \mathrm{~s}^{-1}$ to $100 \mathrm{~s}^{-1}$, the means of the data at $100 \mathrm{~s}^{-1}$ shear rate were calculated at the evaluation. The viscosity values were illustrated as a function of the concentration of CD derivatives.

\section{Surface tension}

The surface tension of the samples was measured with OCA 20 contact angle system (Dataphysics Instruments $\mathrm{GmbH}$, Filderstadt, Germany) by analyzing the shape of pendant drop. The values of surface tension were determined with SCA 20/22 software module using the Young-Laplace equation. ${ }^{27}$ 


\section{Efficacy of antimicrobial preservation}

The applicability of ZnHA-ZnGlu as ophthalmic preservative system was investigated vs BK, because the other components in the formulation could affect its antimicrobial effect. The antimicrobial effectiveness of the ophthalmic samples was determined according to the standards of the European Pharmacopoeia (EP). ZnHA-ZnGlu and BK as preservatives were tested on control strains, Staphylococcus aureus (ATCC 6538), P. aeruginosa (ATCC 9027) and Candida albicans (ATCC 10231). Inoculum suspensions of the microorganisms were prepared by using a sterile suspending fluid containing $9 \mathrm{gL}^{-1} \mathrm{NaCl}$. The number of colony-forming units (CFU) was determined with plate count. The microbial count was about $10^{8} \mathrm{CFU}$ per milliliter. Preserved samples were inoculated with the suspensions of bacteria and fungus by adding $10^{6}$ CFU per milliliter. The volume of the inoculated suspensions of microorganisms did not exceed $1 \%$ of the volume of the product. According to the standard method, three parallel samples were removed at zero hours and at appropriate intervals ( 6 hours, 24 hours, $7 \mathrm{~d}, 14 \mathrm{~d}, 28 \mathrm{~d}$ ), and plated to Sabouraud-dextrose fluid agar (fungus) or tryptic soy fluid agar (bacteria). Bacteria-containing samples were incubated at $30^{\circ} \mathrm{C}-35^{\circ} \mathrm{C}$ for 24 hours and fungus-containing samples at $20^{\circ} \mathrm{C}-25^{\circ} \mathrm{C}$ for 48 hours. The reduction of these values was converted to $\log _{10}$ and compared with requirements $\mathrm{A}$ and $\mathrm{B}$ of the EP (EP-A, EP-B). The requirement of preservative is determined by the EP as the logarithmic reduction of CFU. The effectiveness needed against bacteria and fungus is managed separately. The decrease of CFU needs to be in accordance with the EP-A criteria. In cases when adverse drug reaction can appear with the A criteria, the EP-B criteria are acceptable. ${ }^{28}$ The aim was to determine whether the preservative effect of ZnHA meets the requirements of EP in the presence of $\mathrm{CD}$ derivatives.

\section{Mucoadhesion}

The mucoadhesion of CD-containing eye drops was determined by the tensile test method, based on the measurement of the forces of detachment and the total work of adhesion needed to separate the surfaces, resulting from the area under the force-distance curve. ${ }^{29,30}$ Samples contained two types of CDs (HPBCD and HPGCD) prepared with and without $\mathrm{ZnHA}-\mathrm{ZnGlu}$. The purpose was to determine the effect of ZnHA on mucoadhesion and to establish if the presence of the type of CD has an effect in mucoadhesion. The measurement was performed with a TA.XT Plus Texture analyzer (ENCO, Spinea, Italy) instrument equipped with a $1 \mathrm{~kg}$ load cell and a cylinder probe with a diameter of $1 \mathrm{~cm}$.
The sample $(20 \mu \mathrm{L})$ was attached to the cylinder probe and placed in contact with a filter paper disc wetted with $50 \mu \mathrm{L}$ of an $8 \% \mathrm{w} / \mathrm{w}$ mucin dispersion or simulated lachrymal fluid (blank, $\mathrm{pH}=7.4$ ). The mucin dispersion was made with simulated lachrymal fluid. ${ }^{26,31}$

A 2,500 $\mathrm{mN}$ preload was used for 3 minutes. The cylinder probe was moved upward to separate the sample from the substrate at a prefixed speed of $2.5 \mathrm{~mm} \mathrm{~min}^{-1}$.

\section{Statistical analysis}

One-way and two-way analysis of variances were used to compare the mean values. Statistical analysis was performed by GraphPad Prism five statistical software (GraphPad Software, Inc., La Jolla, CA, USA). The level of significance was set to $P<0.05$.

\section{Results and discussion \\ Phase solubility test}

The phase solubility of PR in HPBCD- and HPGCD-containing aqueous solutions $(0-150 \mathrm{mM})$ is shown in Figure 1.

The solubility of PR was increased linearly by increasing the concentration of HPBCD or HPGCD. The diagrams are Higuchi $A_{L}$ type for both $C D s$, therefore the formation of 1:1 complexes can be assumed. In case of HPBCD, the apparent stability constant of the complex is $1,286.4 \mathrm{M}^{-1}$, and the constant of the PR-HPGCD complex was measured to be $1,778.5 \mathrm{M}^{-1}$.

It is stated that PR has greater affinity for complexformation with HPGCD. With the equation of regression lines, the concentration of $\mathrm{CD}$ needed to solubilize the required amount of API can be determined. These calculated concentrations are the centers of intervals that were used in the drug diffusion study in case of both types of CD derivatives.

\section{Study of diffusion through dialysis membrane}

Eye drops with or without mucoadhesive polymer were formulated and examined. The concentrations of $\mathrm{CD}$ derivatives for the penetration of PR were optimized. The penetrated $P R$ as a function of the concentration of $C D$ is shown in Figure 2.

The results show that $4 \mathrm{mM}$ HPGCD and $5 \mathrm{mM}$ HPBCD induce the highest diffusion of PR through the dialysis membrane. Under the optimal CD concentration a part of free, hydrophobic drug remained in the pouches. Above the optimal CD level, the excess amount of CD keep the free PR 


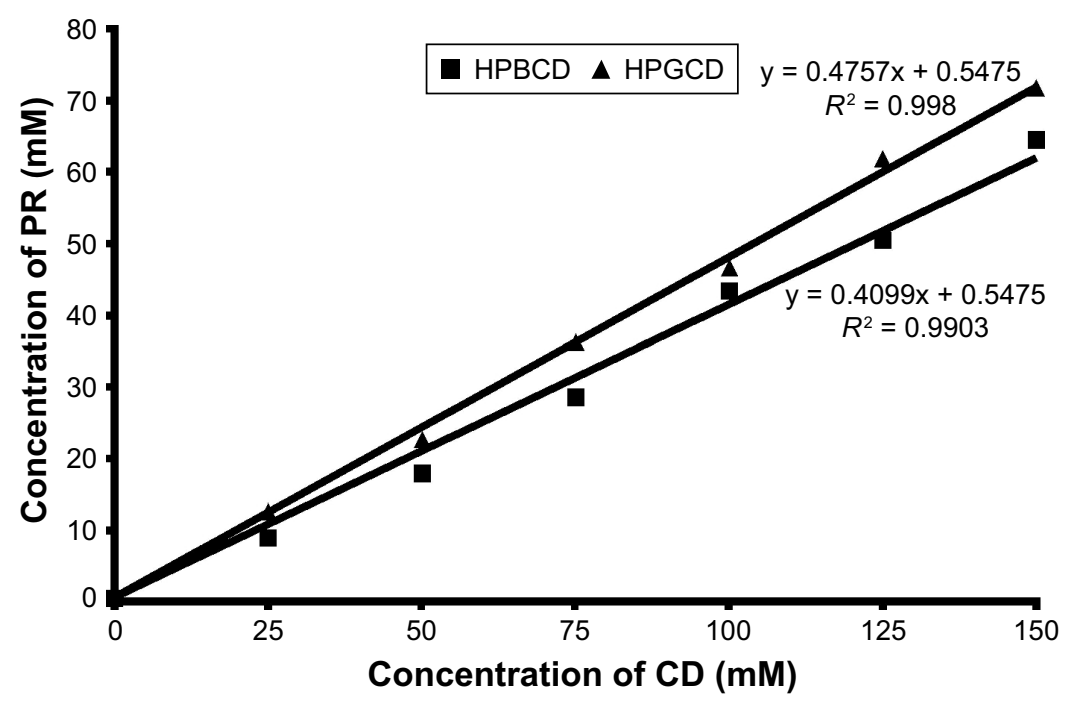

Figure I Phase solubility diagrams of PR in aqueous HPBCD (®) and HPGCD $(\mathbf{\Delta})$ solutions at $25^{\circ} \mathrm{C}$.

Abbreviations: $C D$, cyclodextrin; HPBCD, hydroxypropyl- $\beta$-cyclodextrin; HPGCD, hydroxypropyl- $\gamma$-cyclodextrin; PR, prednisolone.

in complex, therefore less amount of free API is detectable in the acceptor phase.

Thereafter, mucoadhesive $\mathrm{ZnHA}-\mathrm{ZnGlu}$ additives were added to the eye drops, which ensure antimicrobial, preservative effect in the formulations. It was found that the application of biopolymer has no effect on the diffusion of PR. The same amount of drug penetrated through the dialysis membrane at each period in case of both compositions (Figure 3).

\section{Viscosity}

The viscosity of ZnHA and PR-CD complex-containing ophthalmic formulations was measured. The results are shown in Table 1.

According to previous reports, the viscosity should be under $30 \mathrm{mPa} \mathrm{s} .^{32,33}$ Above this level, blurred vision and discomfort appear, which result in faster elimination due to reflex mechanisms of the eye. The results show that the viscosity of our formulations is appropriate in the range of 9.2-24.2 $\mathrm{mPa}$.

\section{Surface tension}

The surface tension of normal tear is about $43 \mathrm{mN} \mathrm{m}^{-1} \cdot 34$ It is not optimal if the surface tension of products is much higher than that of the lacrimal fluids because it has an impact on the therapeutic effect of pharmaceutics applied on the eye, through affecting the spreading of the eye drops on the ocular surface, although no regular critical parameter was found for the surface tension of eye drops in the EP. The surface tension of formulations preserved with $\mathrm{ZnHA}$ was measured by using an OCA 20 contact angle system. The results are shown in Table 2.

No significant difference was found between the values. The surface tensions of the eye drops are about $60 \mathrm{mN} \mathrm{m}^{-1}$,
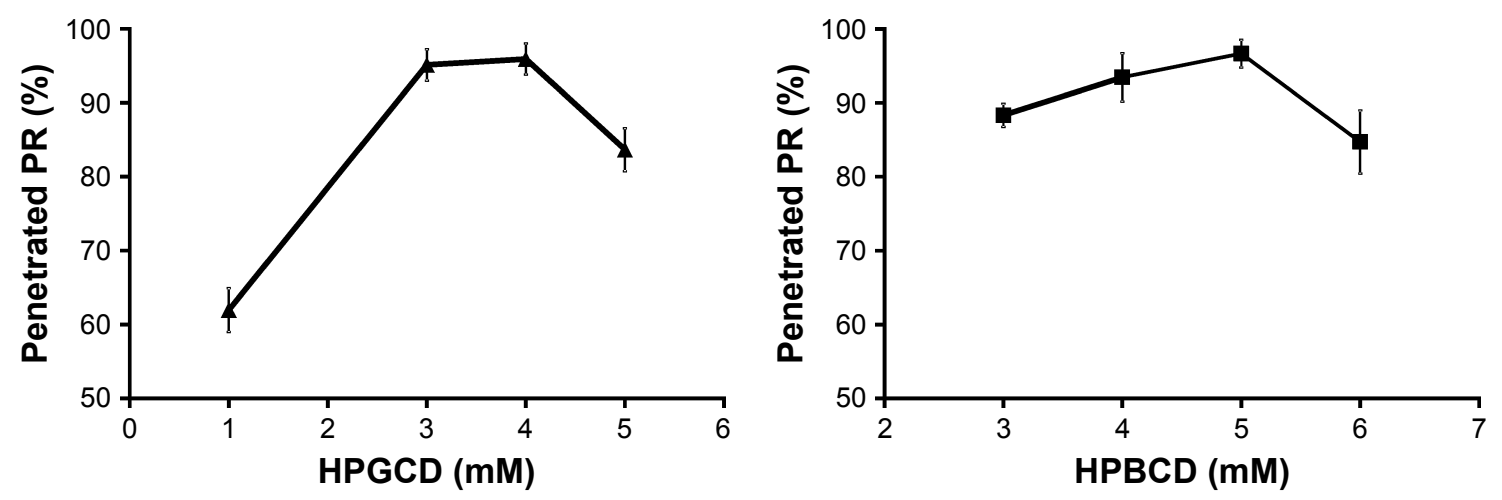

Figure 2 PR diffusion through dialysis membrane as a function of the concentration of HPGCD and HPBCD after 240 minutes. Abbreviations: HPBCD, hydroxypropyl- $\beta$-cyclodextrin; HPGCD, hydroxypropyl- $\gamma$-cyclodextrin; PR, prednisolone. 


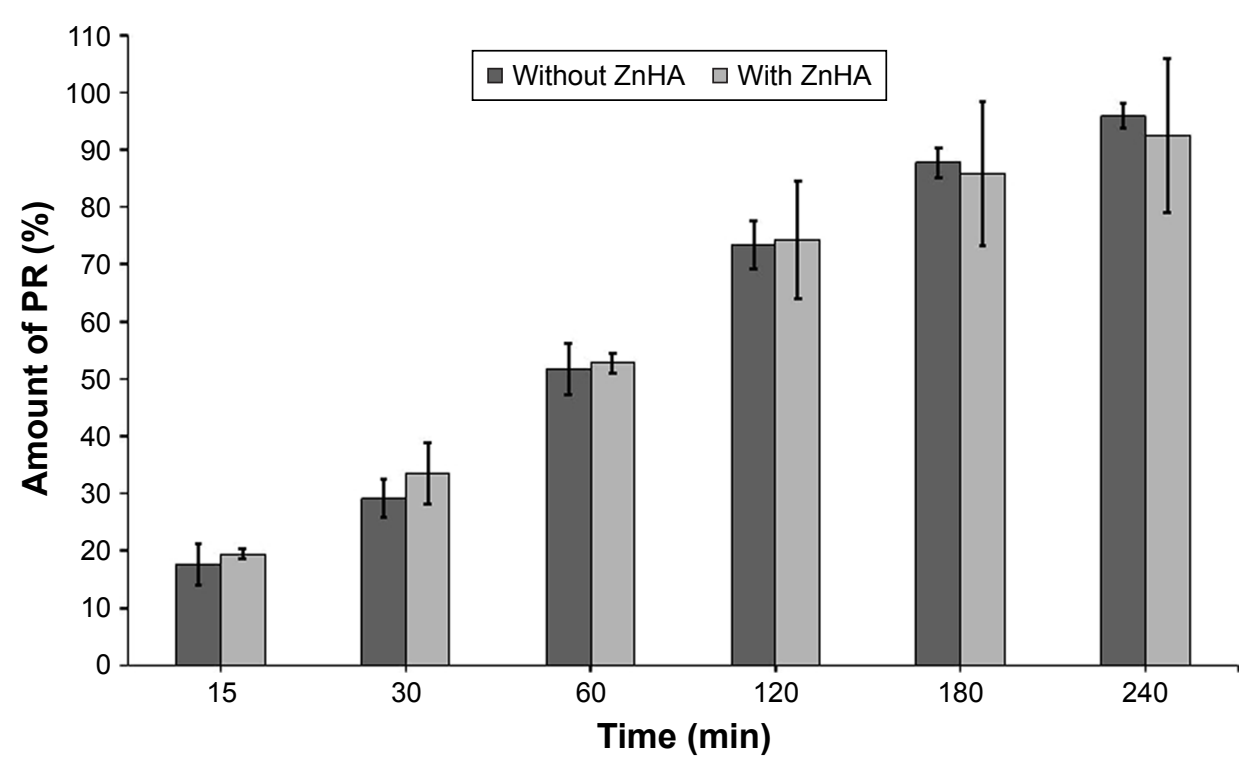

Figure 3 Effect of ZnHA-ZnGlu on the diffusion of PR through dialysis membrane (light column: with ZnHA-ZnGlu; dark column: without ZnHA-ZnGlu). Abbreviations: PR, prednisolone; ZnGlu, zinc-gluconate; ZnHA, zinc-hyaluronate.

which is higher than the surface tension of lacrimal fluid. Ophthalmic products were investigated by Han et al, and the range of the surface tension values was between $34.3 \mathrm{mN} \mathrm{m}^{-1}$ and $70.9 \mathrm{mN} \mathrm{m}^{-1} .{ }^{35-37}$ According to this study, the surface tension of formulations meets the requirements for ophthalmic products.

\section{Efficacy of antimicrobial preservation} In Samples I (with HPBCD) and II (with HPGCD), ZnHA$\mathrm{ZnGlu}$ were used as preservative compounds. The results are shown in Table 3.

The logarithmic decrease of $S$. aureus was 1.5 after 6 hours, 2 after 24 hours, and no bacteria were detected in the samples after 7 days. In case of $P$. aeruginosa, the logarithmic decrease is higher at the earlier period, but the bacterium appeared in every sample. The logarithmic decrease of C. albicans was 1 after 6 hours, and no fungi were detected

Table I Viscosity values of ZnHA-PR-HPGCD (I)- and ZnHAPR-HPBCD (II)-containing products

\begin{tabular}{llll}
\hline & $\begin{array}{l}\text { Concentration } \\
\text { of CD }(\mathbf{m M})\end{array}$ & $\begin{array}{l}\text { Viscosity } \\
(\mathbf{m P a})\end{array}$ & SD \\
\hline I & 3 & 22.8 & 4.5 \\
& 4 & 9.2 & 3.3 \\
II & 5 & 19.7 & 1.2 \\
& 3 & 24.2 & 3.4 \\
& 4 & 18.4 & 2.8 \\
& 5 & 18.1 & 0.7 \\
& 6 & 22.1 & 3.7 \\
\hline
\end{tabular}

Abbreviations: $C D$, cyclodextrin; HPBCD, hydroxypropyl- $\beta$-cyclodextrin; HPGCD, hydroxypropyl- $\gamma$-cyclodextrin; PR, prednisolone; ZnHA, zinc-hyaluronate. later. In summary, the preservative effect of ZnHA-ZnGlucontaining samples meets the EP-B criteria. The antimicrobial effectiveness of ZnHA-ZnGlu is lower against $P$. aeruginosa compared with the other microorganisms.

The microbiological stability of Samples III (with HPBCD) and IV (with HPGCD), which contained BK as a preservative agent, was tested (Table 4).

The logarithmic decrease of $S$. aureus was 1 after 6 hours, 2 after 24 hours, and no bacteria were detected later in Sample III. For $P$. aeruginosa the logarithmic decrease was two and no change was detected later. In C. albicans-containing samples, no fungi were found after 7 days. In Sample IV, for $S$. aureus and C. albicans, the number of CFU was zero after 6 hours. In case of $P$. aeruginosa, the antimicrobial effect was lower due to the known resistance of the bacterium against BK. The microbiological stability of Samples III and IV meets the requirements of the EP. In Sample III, the

Table 2 Surface tension of ZnHA-PR-HPGCD (I)- and ZnHAPR-HPBCD (II)-containing formulations

\begin{tabular}{llll}
\hline $\begin{array}{l}\text { Concentration } \\
\text { of } \mathrm{CD}(\mathrm{mM})\end{array}$ & $\begin{array}{l}\text { Surface tension } \\
\left(\mathrm{mNm}^{-1}\right)\end{array}$ & SD \\
\hline I & 3 & 61.12 & 0.24 \\
& 4 & 61.65 & 0.31 \\
$\mathrm{II}$ & 5 & 61.20 & 0.24 \\
& 3 & 59.31 & 0.15 \\
& 4 & 59.46 & 0.23 \\
& 5 & 58.65 & 0.22 \\
6 & 59.06 & 0.37 \\
\hline
\end{tabular}

Abbreviations: $C D$, cyclodextrin; HPBCD, hydroxypropyl- $\beta$-cyclodextrin; HPGCD, hydroxypropyl- $\gamma$-cyclodextrin; PR, prednisolone; ZnHA, zinc-hyaluronate. 
Table 3 Preservative effectiveness against Staphylococcus aureus, Pseudomonas aeruginosa and Candida albicans in Samples I and II

\begin{tabular}{llllll}
\hline \multicolumn{7}{l}{ Microbial log reduction } \\
\hline \multicolumn{7}{l}{$\mathbf{6}$ hours } & $\mathbf{2 4}$ hours & $\mathbf{7}$ days & $\mathbf{1 4}$ days & $\mathbf{2 8}$ days \\
\hline S. aureus & & & & & \\
Sample I & I.5 & 2 & nd & nd & nd \\
Sample II & I.5 & 2 & nd & nd & nd \\
Criteria (B) & - & I & 3 & - & ni \\
P. aeruginosa & & & & & \\
$\quad$ Sample I & 2 & 3 & - & 4 & - \\
Sample II & 2 & - & 3 & 4 & - \\
Criteria (B) & - & I & 3 & - & ni \\
C. albicans & & & & & \\
$\quad$ Sample I & I.5 & - & - & - & nd \\
Sample II & I & - & - & - & nd \\
Criteria (B) & - & - & - & I & ni \\
\hline
\end{tabular}

Abbreviations: nd, not detectable; ni, no increase.

antimicrobial effect of BK is lower than in Sample IV. It can be assumed that there is a competition between PR and BK for the cavity of HPBCD, so the preservative effect of BK is decreased by the inclusion complex formation. ${ }^{38}$

According to the EP-B criteria, 0.5\% ZnHA-ZnGlu compounds ensure the proper microbiological stability of eye drop formulations. In case of $P$. aeruginosa, the antimicrobial effect of the ZnHA-ZnGlu system is higher than the effect of BK. Considering these results with the irritative attribute of BK, application of $\mathrm{ZnHA}-\mathrm{ZnGlu}$ as a preservative can be favorable in ophthalmic products.

\section{Mucoadhesion}

The measured adhesive force values are shown in Figure 4. Lachrymal fluid was used as blank.

Table 4 Preservative effectiveness in Samples III and IV against Staphylococcus aureus, Pseudomonas aeruginosa and Candida albicans

\begin{tabular}{|c|c|c|c|c|c|}
\hline \multicolumn{6}{|c|}{ Microbial log reduction } \\
\hline & 6 hours & 24 hours & 7 days & I 4 days & 28 days \\
\hline \multicolumn{6}{|l|}{ S. aureus } \\
\hline Sample III & 1 & 2 & nd & nd & nd \\
\hline Sample IV & nd & nd & nd & nd & nd \\
\hline Criteria (B) & - & 1 & 3 & - & $\mathrm{ni}$ \\
\hline \multicolumn{6}{|l|}{ P. aeruginosa } \\
\hline Sample III & 2 & - & - & - & - \\
\hline Sample IV & 3 & 2 & - & 3 & - \\
\hline Criteria (B) & - & I & 3 & - & $\mathrm{ni}$ \\
\hline \multicolumn{6}{|l|}{ C. albicans } \\
\hline Sample III & 1 & - & nd & nd & nd \\
\hline Sample IV & nd & nd & nd & nd & nd \\
\hline Criteria $(\mathrm{A})$ & - & - & 2 & - & ni \\
\hline
\end{tabular}

Abbreviations: nd, not detectable; ni, no increase.
There is a large difference in the measured force between the blank and the mucin dispersion. All the samples show mucoadhesivity; samples prepared with ZnHA have significantly higher values than samples prepared without it. This proves the importance of the presence of ZnHA because the interpenetration between the ZnHA chains and mucin can be assumed. These samples can have better mucoadhesive properties and cause decreased administration frequency and a lower active ingredient concentration.

The type of CD does not play an important role in mucoadhesion because there is no significant difference between the samples prepared with HPBCD and HPGCD. According to the results, it can be established that $\mathrm{ZnHA}$ plays an important role in mucoadhesion.

\section{Conclusion}

To increase the bioavailability of steroid-containing ophthalmic products is a great challenge. Over the years, there have been numerous attempts to enhance the efficacy of eye drops. Our aim was to formulate PR-containing aqueous solutions by $\mathrm{CD}$ inclusion complex and to create mucoadhesive eye drops using antimicrobial ZnHA and ZnGlu, with suitable physiological parameters.

Aqueous solutions of PR were formulated by inclusion complexation with HPBCD and HPGCD. The investigation of the diffusion of $\mathrm{PR}$ through the dialysis membrane revealed that $5 \mathrm{mM}$ of HPBCD, and $4 \mathrm{mM}$ of HPGCD caused the highest penetration of API in in vitro circumstances. The addition of ZnHA and ZnGlu had no effect on the penetration properties. The measurement of viscosity showed that the 5-mM HPBCD- and 4-mM HPGCD-containing products had the lowest viscosity values, meeting the requirements of the EP. It was found that the concentration of CDs has no effect on the surface tension of the eye drops, and these values are optimal compared with previously investigated ophthalmic products. The mucoadhesive properties of ZnHA-containing formulations were proved with the tensile test, resulting in a higher retention time of the eye drop on the surface. The type of $\mathrm{CD}$ derivative has no influence on mucoadhesivity. During the preservative effectiveness test, it was proven that the ZnHA-ZnGlu combination is applicable as an antimicrobial, preservative compound. The microbiological stability of ZnHAcontaining products meets the requirements of the EP in case of $S$. aureus, $P$. aeruginosa and $C$. albicans. It can be stated that BK with unfavorable toxicity properties for the corneal epithelial cells can be replaced with the more biocompatible ZnHA. 


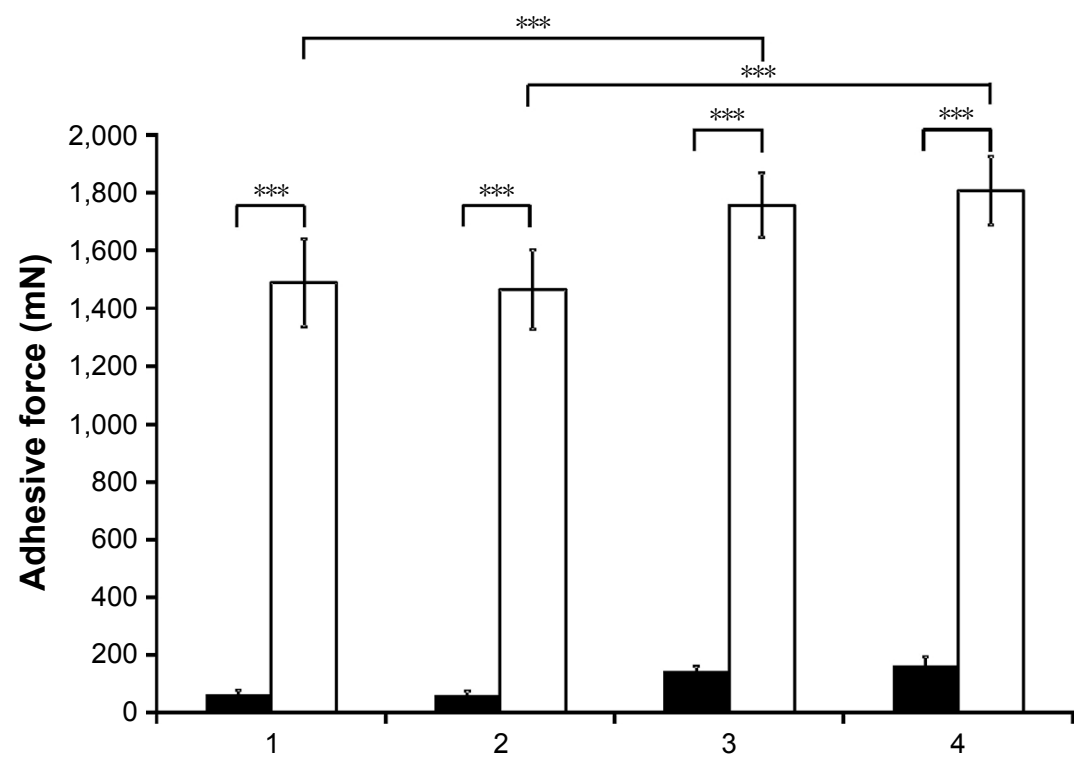

Figure 4 Adhesive force of eye drops with (white columns) and without mucin (black columns) (I, with HPBCD; 2, with HPGCD; 3, with HPBCD and ZnHA-ZnGlu; 4, with HPGCD and $\mathrm{ZnHA}-\mathrm{ZnGlu}$ ). The asterisks mark the significant difference between the results. The analysis was performed by the written statistical software and method.

Abbreviations: HPBCD, hydroxypropyl- $\beta$-cyclodextrin; HPGCD, hydroxypropyl- $\gamma$-cyclodextrin; ZnGlu, zinc-gluconate; ZnHA, zinc-hyaluronate.

In summary, anti-inflammatory ophthalmic products containing PR with enhanced bioavailability were formulated in aqueous solutions by means of $\mathrm{CD}$ inclusion complex formation with optimal mucoadhesion and antimicrobial properties. Although further experiments such as toxicity and permeation studies are needed, these results are promising for the formulation of innovative eye drops with high therapeutic effect and sufficient patient compliance.

\section{Acknowledgments}

The project was supported by the European Union and cofinanced by the European Social Fund: TAMOP-4.2.2.A11/1/KONV-2012-0035. The authors would like to thank Cyclolab Ltd for their material support.

\section{Disclosure}

The author reports no conflicts of interest in this work.

\section{References}

1. Kaur IP, Kanwar M. Ocular preparations: the formulation approach. Drug Dev Ind Pharm. 2002;28(5):473-493.

2. Loftsson T, Stefánsson E. Cyclodextrins in eye drop formulations: enhanced topical delivery of corticosteroids to the eye. Acta Ophthalmol Scand. 2002;80(2):144-150.

3. Kuno N, Fujii S. Recent advances in ocular drug delivery systems. Polymers. 2011;3(1):193-221.

4. Loftsson T, Stefánsson E. Effect of cyclodextrins on topical drug delivery to the eye. Drug Dev Ind Pharm. 1997;23(5):473-481.

5. Challa R, Ahuja A, Ali J, Khar RK. Cyclodextrins in drug delivery: an updated review. AAPS PharmSciTech. 2005;6(2):E329-E357.
6. Loftsson T, Duchêne D. Cyclodextrins and their pharmaceutical applications. Int J Pharm. 2007;329(1-2):1-11.

7. Szente L, Szejtli J. Highly soluble cyclodextrin derivatives: chemistry, properties, and trends in development. Adv Drug Deliv Rev. 1999; 36(1):17-28.

8. Loftsson T, Friðriksdóttir H, Thórisdóttir S, et al. 2-hydroxypropyl$\beta$-cyclodextrin in topical carbonic anhydrase inhibitor formulations. Eur J Pharm Sci. 1994;1(4):175-180.

9. Saarinen-Savolainen P, Järvinen T, Araki-Sasaki K, Watanabe H, Urtti A. Evaluation of cytotoxicity of various ophthalmic drugs, eye drop excipients and cyclodextrins in an immortalized human corneal epithelial cell line. Pharm Res. 1998;15(8):1275-1280.

10. Kiss T, Fenyvesi F, Bácskay I, et al. Evaluation of the cytotoxicity of beta-cyclodextrin derivatives: evidence for the role of cholesterol extraction. Eur J Pharm Sci. 2010;40(4):376-380.

11. Järvinen $\mathrm{K}$, Järvinen $\mathrm{T}$, Urtti A. Ocular absorption following topical delivery. Adv Drug Deliv Rev. 1995;16(1):3-19.

12. Andrews GP, Laverty TP, Jones DS. Mucoadhesive polymeric platforms for controlled drug delivery. Eur J Pharm Biopharm. 2009;71(3): 505-518.

13. Mansuri S, Kesharwani P, Jain K, Tekade RK, Jain NK, et al. Mucoadhesion: a promising approach in drug delivery system. React Funct Polym. 2016;100:151-172.

14. Guter M, Breunig M. Hyaluronan as a promising excipient for ocular drug delivery. Eur J Pharm Biopharm. 2017;113:34-49.

15. Lai JY, Tu IH. Adhesion, phenotypic expression, and biosynthetic capacity of corneal keratocytes on surfaces coated with hyaluronic acid of different molecular weights. Acta Biomater. 2012;8(3):1068-1079.

16. Horvát G, Gyarmati B, Berkó Sz, et al. Thiolated poly(aspartic acid) as potential in situ gelling, ocular mucoadhesive drug delivery system. Eur J Pharm Sci. 2015;67:1-11.

17. Chapman JM, Cheeks L, Green K. Interactions of benzalkonium chloride with soft and hard contact lenses. Arch Ophthalmol. 1990; 108(2):244-246.

18. Swiercz R, Hałatek T, Majcherek W, Grzelińiska Z, Wasowicz W. Toxic effect of benzalkonium chloride on animals and humans. Med Pr. 2007;58(2):139-142. 
19. Ye J, Wu H, Zhang H, et al. Role of benzalkonium chloride in DNA strand breaks in human corneal epithelial cells. Graefes Arch Clin Exp Ophthalmol. 2011;249(11):1681-1687.

20. Sakagami Y, Yokoyama H, Nishimura H, Ose Y, Tashima T. Mechanism of resistance to benzalkonium chloride by Pseudomonas aeruginosa. Appl Environ Microbiol. 1989;55(8):2036-2040.

21. Pasquet J, Chevalier Y, Couval E, Bouvier D, Bolzinger MA. Zinc oxide as a new antimicrobial preservative of topical products: interactions with common formulation ingredients. Int J Pharm. 2015;479(1):88-95.

22. Illés J, Jávor A, Szíjártó E. Zinc-hyaluronate: an original organotherapeutic compound of Gedeon Richter Ltd. Acta Pharm Hung. 2002; 72(1):15-24

23. Sandri G, Bonferoni MC, Rossi S, et al. Thermosensitive eyedrops containing platelet lysate for the treatment of corneal ulcers. Int $J$ Pharm. 2012;426(1-2):1-6.

24. Higuchi T, Connors KA. Phase-solubility techniques. In: Reily CN, editor. Advances in Analytical Chemistry and Instrumentation. Vol. 4. New York: Interscience; 1965:117-212.

25. Repta AJ. Alteration of apparent solubility through complexation. In Yalkowski SH, editor. Techniques of Solubilization of Drugs. New York Marcel Dekker; 1985:135-157.

26. Horvát G, Budai-Szücs M, Berkó Sz, Csányi E, et al. Comparative study of nanosized cross-linked sodium-, linear sodium- and zinc-hyaluronate as potential ocular mucoadhesive drug delivery systems. Int J Pharm 2015;494(1):321-328.

27. Dataphysics. Operating Manual OCA (OCA 5, OCA 10, OCA 15, OCA 15 plus, OCA 20, OCA 30, OCAH 200 and OCAH 230); 2002:71.

28. European Directorate for Quality of Medicines. Efficacy of Antimicrobial Preservation. European Pharmacopoeia. 9th ed. Strasbourg European Directorate for the Quality of Medicines; 2006:5129-5130.
29. Cappello B, de Rosa G, Giannini L, et al. Cyclodextrin-containing poly(ethyleneoxide) tablets for the delivery of poorly soluble drugs: potential as buccal delivery system. Int J Pharm. 2006;319(1-2): $63-70$

30. Woertz C, Preis M, Breitkreutz J, Kleinebudde P. Assessment of test methods evaluating mucoadhesive polymers and dosage forms: an overview. Eur J Pharm Biopharm. 2013;85(3 Pt B):843-853.

31. Szűcs M, Sandri G, Bonferoni MC, et al. Mucoadhesive behaviour of emulsions containing polymeric emulsifier. Eur J Pharm Sci. 2008; 34(4-5):226-235.

32. Oechsner M, Keipert S. Polyacrylic acid/polyvinylpyrrolidone bipolymeric systems. I. Rheological and mucoadhesive properties of formulations potentially useful for the treatment of dry-eye-syndrome. Eur $J$ Pharm Biopharm. 1999;47(2):113-118.

33. Salzillo R, Schiraldi C, Corsuto L, et al. Optimization of hyaluronanbased eye drop formulations. Carbohydr Polym. 2016;153:275-283.

34. Tiffany JM, Winter N, Bliss G. Tear film stability and tear surface tension. Curr Eye Res. 1989;8(5):507-515.

35. Han K, Woghiren OE, Priefer R. Surface tension examination of various liquid oral, nasal, and ophthalmic dosage forms. Chem Cent J. 2016;10:31.

36. Hotujac Grgurević M, Juretić M, Hafner A, Lovrić J, Pepić I. Tear fluid-eye drops compatibility assessment using surface tension. Drug Dev Ind Pharm. 2017;43(2):275-282.

37. Doschi U, Xu J. Effect of viscosity, surface tension and mucoadhesion on ocular residence time of lubricant eye drops. Invest Ophthalmol Vis Sci. 2009;50:4641

38. Loftsson T, Stefánsdóttir Ó, Friôriksdóttir H, Guômundsson Ö, et al. Interactions between preservatives and 2-hydroxypropyl- $\beta$-cyclodextrin Drug Dev Ind Pharm. 1992;18(13):1477-1484.

\section{Publish your work in this journal}

Drug Design, Development and Therapy is an international, peerreviewed open-access journal that spans the spectrum of drug design and development through to clinical applications. Clinical outcomes, patient safety, and programs for the development and effective, safe, and sustained use of medicines are the features of the journal, which

\section{Dovepress}

has also been accepted for indexing on PubMed Central. The manuscript management system is completely online and includes a very quick and fair peer-review system, which is all easy to use. Visit http://www.dovepress.com/testimonials.php to read real quotes from published authors.

Submit your manuscript here: http://www.dovepress.com/drug-design-development-and-therapy-journal 